\title{
Protected-area planning in the Brazilian Amazon should prioritize additionality and permanence, not leakage mitigation
}

\section{Abstract}

2 The establishment of protected areas (PAs) where human land uses are restricted, especially in

3 Amazonian forests, is an important bulwark against global biodiversity collapse and climate change.

4 Here we assess if restriction of land clearing within Amazonian PAs displaces deforestation pressure

5 to adjacent forests, a spillover effect called leakage, or if it further inhibits deforestation around PAs,

6 a spillover effect called blockage. Leakage can undermine the net impact achieved by PA

7 establishment. We calculated the non-target and target impacts of 91 state-governed (non-

8 indigenous) PAs established between 2005 and 2016 on satellite monitored deforestation rates. We

9 then assessed how well the features of PAs, like size and restriction level, explain the spillovers. On

10 average less than $2 \%$ of the assessed spillover zone was deforested above (leakage) or below

11 (blockage) the area expected to have been deforested without nearby PA establishment. Blockages outnumbered leakages regardless of the method adopted to calculate the deforestation baseline rate. Our results suggest the establishment of PAs has inhibited deforestation both within their boundaries and in their adjacent surroundings. The 17 PAs that did not inhibit deforestation within their boundaries and the 19 PAs where leakage occurred were geographically concentrated in southern and western regions of Amazônia Legal. High-magnitude leakage of deforestation pressure from PAs to their adjacent surroundings seems therefore to be rare in the Brazilian Amazon. For the most effective conservation of Amazonian forests, priority should be given to achieving additionality with any new PA and ensuring the permanence and enforcement of those already established.

\section{Keywords}




\section{Introduction}

The global protected area (PA) estate is an important contributor to both biodiversity conservation and climate change mitigation goals, especially in the humid tropics (Nelson and Chomitz 2011). PAs are the principle defence of animal habitat as global mass extinction unfolds (Pimm and Raven 2000), and safeguarding forests from unrestricted human encroachment and development is an effective, low cost, natural climate change mitigation strategy (Griscom et al. 2017). While the conservation impact of PA establishment within the target area is presumably positive (Nagendra 2008; Naughton-Treves et al. 2005), the associated impact on its surroundings (i.e. the non-target impact, or spillover) may be negative, positive, or negligible; both the target and non-target impacts are components of the net impact of establishing a PA within a landscape (Bode et al. 2015; Ewers and Rodrigues 2008; Renwick et al. 2015).

In the case of "leakage," the negative type of spillover, clearing or other land-use change that is restricted in the target area is displaced to an area where it would not otherwise have occurred (Aukland et al. 2003; Ewers and Rodrigues 2008). Leakage can undermine or entirely offset PAs' net impact for conservation (Bode et al. 2015; Renwick et al. 2015) and carbon sequestration (Ostwald and Henders 2014), whilst falsely exaggerating assessments of PA effectiveness and accelerating the rate at which PAs become isolated and the landscape becomes fragmented (Ewers and Rodrigues 2008), shortening the window of opportunity to achieve a representative and well connected PA network (Fearnside 2009). Further, if clearing is displaced from locations opportunistically protected, i.e. under protection because of their remoteness and/or low economic value, rather than their environmental value (Pressey et al. 1993), to other areas containing more highly irreplaceable and vulnerable habitat or greater carbon storage capacity, PA establishment could do more harm than good (Bode et al. 2015; Renwick et al. 2015). Despite these concerns, leakages from PAs have rarely been systematically quantified (Fuller et al. 2019). Leakage monitoring and mitigation should be a component of a global push to target quality over quantity in PA target development, as leakage is amongst the perverse outcomes of prioritising area-based targets (Barnes et al. 2018).

The beneficial type of spillover, termed "blockage", can also occur, whereby conservation achievements expand beyond the legal boundary of a PA. In terrestrial forested ecosystems, blockage may occur if deforestation is discouraged by the presence of a nearby PA, perhaps due to a flourishing ecotourism industry or reduced incentive for regional infrastructure investment (Herrera Garcia 2015). Blockage effects may be visible from aerial or remote sensed imagery as "haloes" of intact vegetation around a PA's border, demonstrating that adjacent forest cover has been protected from clearing by de facto rather than de jure means (Herrera Garcia 2015).

Detection of spillover, crucial for measuring the net impact of PA establishment, can inform systematic conservation planning (Ferraro and Pattanayak 2006; Margules and Pressey 2000) by ensuring spatial prioritization of a PA network that is the best possible bulwark against the planetary scale problems of biodiversity collapse and climate change. Yet, in spite of the recent availability of widespread spatially explicit, multi-temporal deforestation and land use/land-use change data, spillover effects are infrequently accounted for in PA assessments (Fuller et al. 2019; Miteva et al. 2012; Pfaff and Robalino 2017). As such, little is known about why some land-use change restrictions, like those assessed in Peru (Oliveira et al. 2007), have generated leakage whilst others, like those assessed in Costa Rica and Ecuador, have generated either negligible spillovers or blockages (Andam et al. 2008; Robalino et al. 2017; Tapia-Armijos et al. 2017). An understanding of the prevalence, direction, magnitude, and drivers of past spillovers is critical for predicting and avoiding future leakage events. Such understanding is vital for avoiding scenarios where investments in PA establishment result in only nominal gains for habitat conservation and carbon storage, and for avoiding a worst-case scenario whereby land clearing is displaced from PAs to more vulnerable and irreplaceable habitats or to areas more important for climate change mitigation. To that end, we 
calculate and analyze the target and non-target impacts of recent PA establishments in an especially biodiversity- and carbon-rich forested region: Brazil's Amazônia Legal.

The PA network of Amazônia Legal is an ideal case study as it is recognized as a globally important area for biodiversity conservation (Mittermeier et al. 2003) and climate change mitigation (Nepstad et al. 2008; Soares-Filho et al. 2010). Brazil's 3201 terrestrial PAs make up one of the largest networks in the world; approximately $30 \%$ of the country's area is protected. About $88 \%$ of the country's protected area network is located within Amazônia Legal (UNEP-WCMC and IUCN 2019). Impact assessment that accounts for spillover is possible here because deforestation has been monitored and reported in Brazilian Amazon since 2005, and PAs in this region have significantly inhibited deforestation within their target areas (Fearnside 2008b; Ferreira et al. 2005; Nepstad et al. 2006; Vitel et al. 2009). Unlike previous research on deforestation inhibition by PAs (Nagendra 2008), in this study we aimed to account for deviation of post-PA establishment clearing rates from the baseline, i.e., the deforestation rate that would have been expected without PA establishment, when calculating impact values (Pressey et al. 2017). We quantified both components of PAs' net impact on the landscape: (1) deforestation within PAs, and (2) deforestation in the unprotected, adjacent surroundings. We identified PAs with evidence of leakage or blockage and then tested key PA features for association with high magnitude spillovers.

\section{Materials and Methods}

\subsection{Study area}

Amazônia Legal is a $5016136 \mathrm{~km}^{2}$ administrative region of Brazil that includes the entire states of Acre, Amapá, Amazonas, Pará, Rondônia, Roraima and Tocantins, as well as part of Mato Grosso and Maranhão (Fig. 1); it is home to a population of approximately 24 million people. As of 2017 Amazônia Legal contained 340 conservation PAs and 459 Indigenous Lands (Fig. 1). We assessed the 91 state-governed (non-indigenous) PAs, including 15 privately owned PAs, established during the period 2005 to 2016, which range in size from less than $1 \mathrm{~km}^{2}$ to $36102 \mathrm{~km}^{2}$, with a mean size of $4666 \mathrm{~km}^{2}$ across the sample (see online supporting information, Table S1). High-resolution deforestation data is not reported prior to 2005, and thus PAs established before 2005 were not assessed. Indigenous lands were not assessed because they may not be managed specifically for deforestation inhibition, although they have been shown to be effective for that purpose (Nolte et al. 2013; Nepstad et al. 2006) as well as being important for vertebrate biodiversity conservation in Brazil (Schuster et al. 2019).

Various actors are implicated in the deforestation dynamics of Amazônia Legal: grileiros or illegal land grabbers, loggers and sawmillers, ranchers and their employees, unorganized landless migrants, organized "sem terra" landless rural workers, agribusiness-scale soy farmers, and miners (Fearnside 2008a). Land tenure is not always uniformly regulated under the rule of law; and changing commodity markets affect human migration and thus clearing (Fearnside 2008a). Leakage may occur where small farmers are displaced from newly protected forests or where crop production is displaced and affects supply and demand dynamics (Fearnside 2009). The type of leakage whereby grilagem (illegal land appropriation and clearing) becomes concentrated in the unprotected portions of forest where land tenure is especially unregulated is considered to be the most significant leakage mechanism within the Amazonian PA network (Fearnside 2009). Despite the variety of actors involved, PA location within a given state and PA administration by a particular governance tier warrant testing as drivers of deforestation impacts (Herrera et al. 2019; Pfaff et al. 2014). As Amazonian protected areas' forest impacts have been shown to vary significantly with development pressure (Pfaff et al. 2015a; Pfaff et al. 2015b), we assess six possible factors that may contribute to the intensity of deforestation pressure faced by a given area, and Table S2 in the online supporting 
materials provides the justifications for their inclusion in modelling the impact of PA establishment on deforestation dynamics.

\subsection{Data acquisition}

We obtained data on the location and extent of new clear-cut deforestation for each year from 2005 to 2017 from the Program for Monitoring Deforestation of the Amazon (PROgrama de Cálculo do DESflorestamento na Amazônia, or PRODES, in Portuguese) data set, based on 30-meter resolution LandSat imagery. The government agency responsible for carrying out PRODES, the Instituto Nacional de Pesquisas Espaciais (INPE), made these data publicly available (http://www.dpi.inpe.br/prodesdigital/prodes.php) at the behest of Brazil's Environment Ministry since 2002; this website was discontinued in April 2019. The monitoring program has used a consistent methodology for collecting and reporting these data only since 2005 , and consequently, only data from the period since 2005 were used in this study. Because PRODES only detects and reports clear cuts of $0.0625 \mathrm{~km}^{2}$ or larger, some smaller scale clearing may be missing from this analysis; notably, PRODES does not distinguish between illegal deforestation such as that carried out by grileiros, which all PAs seek to reduce, and the local inhabitants' subsistence tree felling, which may be legally sanctioned in some of the sustainable use units that we assess $(n=47)$. Further, PRODES does not monitor the portion of the Amazon biome that extends beyond Brazil's national borders, and it is possible that some agents of deforestation could have shifted to those areas to avoid detection (Richards et al. 2017).

We obtained data on locations and characteristics of all PAs within Amazônia Legal from Brazil's Environment Ministry (http://mapas.mma.gov.br/i3geo/datadownload.htm). The geographic location of the PAs, as well as associated metadata including year of establishment, whether the Brazilian PA classification is strictly protected or sustainable-use approved, governing tier (federal, state, or municipal), and total area protected, were cross-checked with similar spatial data provided by Protected Planet's World Database on Protected Areas (https://www.protectedplanet.net/). The 91 PAs (Fig. 1) we assessed were chosen because they were established within the spatial and temporal range of PRODES deforestation reporting; that is, they were all established 2005-2016 and are located in the states of Amazonas ( $n=38)$, Pará $(n=33)$, Mato Grosso $(n=7)$, Tocantins ( $n=5)$, Acre $(n=3)$, Rondônia $(n=3)$, and Roraima $(n=2)$. No PAs established in Maranhão or Amapá met our temporal (2005-2016) and spatial (satellite monitoring range) criteria. PA downgrading, downsizing, and degazettement (Table S1) data for this region was obtained from https://www.padddtracker.org/.

\subsection{Assessment of PAs' target and non-target impacts on deforestation rates}

We defined a PA's target impact as the difference between the observed deforestation and the expected deforestation within protection's boundaries; non-target impact is the difference between observed and expected deforestation in the spillover zone, located in the immediately adjacent, unprotected surroundings of the PA. Using QGIS and ArcMap 10.6 software, we defined the spillover zones by creating a buffer around each PA equal in area to the PA (Fig. 1); any non-terrestrial portions of the buffers, in the few cases of coastal PAs, were removed. We then calculated the area newly deforested each year within each PA and within each spillover zone; these values constitute observed annual deforestation.

Estimates, for each year, of the amount of deforestation that would have occurred had the PA never been established, both within the PA and in the spillover zone, were ascertained from deforestation that occurred in samples of the unprotected wider landscape during the same year (Fig. 2); generation of counterfactual baselines that define the wider landscape are necessary to quantify impacts (Ferraro 2009; Pressey et al. 2017). We could only use the baseline estimation method suggested by Ewers and Rodrigues (2008) for 73 of the 91 PAs (Fig. 2b and section 3.1), as the 
remaining 18 PAs were in close proximity, meaning there was not enough 'unprotected land' in their surrounds (Fig. 1) from which to draw landscape samples. As such, we also used a second baseline generation method (Fig. 2c and Table S3) to allow for the assessment of all 91 PAs. We attempt to account for variation in likelihood of clearing by using one highly localized baseline to minimize environmental differences, and one state-based baseline to minimize differences in anthropogenic factors.

\subsubsection{Estimating locally derived baselines}

Following the spillover quantification method suggested by Ewers and Rodrigues (2009), for each of the 73 PAs we generated five random circular sample parcels, located within the unprotected wider landscape but beyond the spillover zone (Fig. 2b). The total area of the five sample parcels was equal to that of the associated spillover zone to allow for direct comparison of areas newly deforested each year in the unprotected landscape, in the spillover zone, and in the PA itself. We constrained the random sample parcels to i) the area within a maximum distance of 10 times their radii from the associated PA's boundary and ii) outside the spillover zones of any of the other 90 PAs. We then calculated the area of deforestation reported for each year in each set of wider landscape samples.

\subsubsection{Estimating state-derived baselines}

A second set of expected annual deforestation for each PA and associated spillover zone was derived from the percent area deforested each year within the unprotected portion of the state in which the given PA is located (online supporting information, Table S3). Forty of the 91 PAs we assessed were administered by state governments, and other key deforestation policies in place in the Amazônia Legal have been applied and enforced at a state-by-state level. For example, the 2012 Forest Code legislation states that the percent of landholders' property that can be legally deforested depends on the state within which that property is located (Freitas et al., 2018). Given the state-by-state nature of legal forest conservation requirement, we estimated these novel baselines for each state and assigned them to PAs and their spillover zones according to PA location. For example, the Extractive Reserve Ariaca Pruano was established in Pará in 2005; the percent of the PA deforested, and the percent of the spillover zone deforested during the years 2006 through 2017, were compared with the percent of the entire unprotected portion of Pará that was deforested during the same years (Fig. 2c). In the few cases of a single PA being located in more than one state $(n=5)$, the baseline values for each year were derived from the state containing the largest portion of the PA's area.

\subsection{Impact calculation}

Spillover (i.e. non-target impact) was calculated for each PA for each year (see online supporting information, Table S4), starting from the year following the given PA's establishment through to 2017. However, any of these spillover calculations were not analyzed if the associated PA did not impact on deforestation within its boundaries. We obtained a net spillover value for each PA by using the following formula:

$$
I_{\text {total }}=\sum_{i=1}^{n}\left(O_{i}-E_{i}\right)
$$

where $I_{\text {total }}$ is the summed impact of all $n$ years of the given PA's existence until 2018,

$O_{i}$ is the observed $\mathrm{km}^{2}$ of new deforestation in the $i^{\text {th }}$ year since the given PA's gazettal, and

$E_{i}$ is the counterfactual estimate of the $\mathrm{km}^{2}$ of new deforestation expected in the $i^{t h}$ year had no PA ever been gazetted. 
A negative spillover value, indicating that there was less deforestation observed than expected, was interpreted as a possible blockage effect; conversely, a positive spillover value indicated possible leakage (Fig. 3). Blockage observed in some years could have offset leakage observed in other years, and vice versa. Some PAs' spillover results were informed by 12 years of deforestation monitoring after their establishment some (e.g. those PAs established in 2005), whereas others were only informed by a single year (e.g. those established in 2016).

The analogous calculation was performed to assess whether each PA achieved a beneficial target impact, i.e. the area inside protection's boundaries experienced less deforestation than expected, or conversely if the PA may be a "paper park" (Di Minin and Toivonen 2015). Paper park status is suggested if protection did not reduce deforestation compared to the baseline expected rate.

\subsection{Evaluation of potential predictors}

We used generalized linear modelling to gain insight into possible drivers of the direction and magnitude of the spillover results obtained. Six predictors were chosen, five of which were features of the PAs: age, area, state, governing tier (federal/state/municipal), category within the Brazilian PA classification system (see online supporting information, Table S1 for PA characteristics and Table S2 for rationales for their inclusion). The sixth predictor was a characteristic of the spillover zones rather than of the PAs themselves: the percent of the spillover zone that overlaps with other PA(s) or with Indigenous Lands (ILS). It might be expected that high percent overlap would bias spillover calculations towards what would otherwise appear to be blockage-directional effects. We calculated overlap both with other conservations units and with ILs because, in the Brazilian Amazon, ILs have achieved significant forest conservation impact within their boundaries (Nepstad et al. 2006; Nolte et al. 2013) and as such should be considered as equivalent to conservation units in terms of possibly influencing deforestation dynamics in the spillover zones.

All possible combinations of potential predictor variables were tested using the leaps library (Lumley 2017) in R ( Core Team 2018) with $k$-fold ( $k=10)$ cross-validation (James et al. 2013) to select the model, and thereby identify the most important variables related to spillover magnitude across PAs. After removing 30 observations for which the PAs' did not have a deforestationinhibiting impact within their boundaries, and thus were considered unlikely to have displaced deforestation pressures to their unprotected surroundings, we fitted a model to 43 remaining net spillover values calculated with the locally derived baseline. We then, after removing 1 observation for which the PA did not impact deforestation within its boundaries, fitted a model to the 90 remaining net spillover values calculated with state-derived baselines.

\section{Results}

\subsection{Target-area impacts of PA establishment}

For the subset of 73 PAs for which a locally derived baseline could be quantified, impact assessment within PA boundaries showed tangible forest conservation benefits. Satellite monitoring by PRODES did not report deforestation in nor around 17 PAs (23\%), and as such their impact could not be quantitatively assessed.

Less deforestation was reported in of 43 (59\%) of the 73 PAs assessed with the locally derived baselines (Fig. 4a), suggesting successful inhibition of deforestation within these PAs' boundaries. For these 43 cases with evidence of successful protection, the net differences between expected and observed deforestation within PA boundaries by 2017 ranged from less than $0.1 \mathrm{~km}^{2}$ to $1250 \mathrm{~km}^{2}$; the mean was more than $127 \mathrm{~km}^{2}$. As percentages of the PA's extent, avoided deforestation ranged from close to $0 \%$ to more than $9 \%$ with a mean of $2.19 \%$. Assessment with the locally derived baselines indicated that only 13 (18\%) of the 73 PAs failed to inhibit deforestation (Fig. 4a). Within the boundaries of these possible paper parks (Di Minin and Toivonen 2015), the area deforested 


\subsection{Non-target area impacts of PA establishment}

\section{Locally derived baseline}

$\begin{array}{ll} & \begin{array}{l}\text { Mean annual } \\ \text { deforestation } \\ \text { Number }\end{array} \\ \text { of } \% \text { of PA) above or } & \text { below baseline rate }\end{array}$

\section{State-derived baseline method}

$\begin{array}{ll} & \begin{array}{l}\text { Mean annual } \\ \text { deforestation } \\ \text { Number }\end{array} \\ \text { (\% of PA) above or } \\ \text { of PAs } & \text { below baseline rate }\end{array}$

$1.747 \%$

Leakage

9

$0.240 \%$

$-2.019 \%$

NA

0

NA

to calculate

18

30

Paper park -

spillover

irrelevant
270

Table 1. Spillover calculated for 91 PAs. See online supporting materials (Table S4) for PA-specific results.

There were only six discrepancies in net spillover outcome (excluding spillovers calculated for paper parks) between the two methods: in five of the six cases, the locally-derived baseline calculation yielded a net leakage result for a PA for which the state-derived baseline calculation yielded blockage; only Acari National Park yielded the opposite type of outcome discrepancy. The first five cases may be explained by the bias of the state-derived baseline method towards indicating blockage rather than leakage. That is, because at least some deforestation occurred in every Amazonian state each year 2006 to 2017 (see online supporting information, Table S3) state-derived baselines expect some deforestation to occur in all PAs' target and spillover zones. 
283 See online supporting information (Fig. S1) for the proportional distribution and number of

blockages/leakages per predictor category. For those PAs where a net leakage effect was identified by 2017 , we observed an increasing trend of (non-cumulative) annual leakage magnitudes, regardless of the baseline method used (Fig. 5). Conversely, for those PAs where a net blockage effect was detected by 2017, no clear temporal trend was observed (Fig. 5). The lack of reported deforestation in and around the PAs that were typically more recently established, small, or municipally administered (see online supporting information, Fig. S1) prohibited calculation of either type of spillover using locally derived baselines for those areas. Regardless of the baseline used in calculation, PA age, size, state, governmental tier, or land-use restriction intensity as denoted by the Brazilian PA classification system, blockage outcomes far outnumbered leakage outcomes (see online supporting information, Table S4 and Fig. S1). Leakages were slightly more prevalent in the subset of PAs in the largest size quartile group (see online supporting information, Fig. S1b).

\subsection{Results of model selection with $\mathbf{k}$-fold cross-validation}

The best-selected model of the 43 net spillover values associated with PAs effective within their boundaries, calculated with locally derived baselines, had a structural goodness-of-fit of $14.1 \% \mathrm{DE}$ (percent deviance explained) and included one of the potential predictors (see online supporting information, Fig. S2a) as a coefficient: PA age (coefficient $=-0.0022$, $p$-value $=0.0217$ ). Older PAs were associated with more negative spillover values, i.e. blockages.

The best-selected model of 90 net spillover values calculated with state-derived baselines had a structural goodness-of-fit of 33.6\%DE, and it included three significant coefficients (see online supporting information, Fig. S2b): PA age (coefficient $=-0.0014, p$-value $=0.0026$ ), PA type in the Brazilian classification system (coefficient $=-0.0080$, $p$-value $=0.0297$ ), and state (coefficient $=$ $0.0177, \mathrm{p}$-value $=0.0428$ ) where only Amazonas was significant. Older PAs and the sustainable use PAs, i.e. those where some resource extraction is allowed under Brazilian law, were significantly associated with negative model coefficients, i.e. blockage outcomes, in the best-selected model. PA location within the state of Amazonas was significantly associated with a positive model coefficient, i.e. leakage outcomes. The percent of the spillover zone overlapped by another area under some kind of protected designation was not found to influence the spillover value calculated.

In summary (see also Fig. 4), model selection with $k$-fold $(k=10)$ cross-validation indicated that PA age was negatively correlated with spillover value and thus implicated in blockage-directional outcomes, regardless of which of the two baseline estimation methods was used to generate the spillover values modelled. Neither the PA's governing tier (federal, state, or municipal) nor the percent of the spillover zone overlapped by other PAs or ILs was an important predictor of the spillover value calculated (see online supporting information, Table S2 and Fig. S2).

\section{Discussion}

A growing body of literature calls for explicit spillover accounting in conservation policy impact assessments (Ewers and Rodrigues 2008; Miteva et al. 2012; Pfaff and Robalino 2017). Even if only legally protected forests are likely to remain in the Amazônia Legal in the long term, e.g., 100 years from now, leakage from PAs established now still poses a problem: leakage reduces the temporal window of opportunity to establish a biologically representative PA network with maximized connectivity within the remaining unprotected landscape (Fearnside 2009). That crucial window of opportunity is reduced in a $100 \%$ leakage scenario, whereby displaced deforestation pressure causes clearing to occur in an unprotected area equal in size to the area under protected status; a $0 \%$ 
leakage scenario does not reduce that window of opportunity (Fearnside 2009). Given that the mean value of the net leakages we detected was less than $2 \%$ of the associated PAs' areas, regardless of the baseline used in calculation, leakage in this region and during this period is unlikely to have shortened the window of opportunity for designing and building an optimized PA network in Amazônia Legal before a future equilibrium state of forested and cleared land is reached. Indeed, detection of leakage was rare: assessments of the 91 PAs' unprotected adjacent surroundings found more evidence of blockage than of leakage, regardless of the baseline used to calculate impact. Model selection analysis showed that older PAs were more likely to be associated with net blockage outcomes by 2017, but it is possible that our sample of 91 recently established Amazonian PAs may not be representative of spillover dynamics of yet older PAs.

The results from our sample of PAs nonetheless further affirm the beneficial target impact of recent PA establishments in Amazônia Legal for forest conservation. Congruent with past studies (Nagendra 2008), our assessment of the areas within PAs' boundaries detected overwhelmingly more evidence of effective deforestation inhibition than evidence of paper parks, regardless of which baseline was used to calculate impact. Given the general effectiveness of these PAs to inhibit deforestation within their boundaries, it is important that they not be downgraded, downsized, or degazetted: PA downgrading, downsizing, or degazettement (Kroner et al. 2019; Mascia and Pailler 2011; Pack et al. 2016) was proposed at some point after the establishment of 13 of the 91 PAs we assessed. Two PAs, Floresta Estadual do Paru and Parque Nacional Mapinguari, saw downsizing proposals enacted in 2012 (see online supporting information, Table S1).

The few possible paper parks, i.e. those PAs associated with being ineffective within their boundaries, and the PAs associated with the highest magnitude leakages are geographically aggregated in the south and west of the study area (Fig. 4). This trend is congruent with the model selection analysis' identification of PAs location within the western state of Amazonas being more associated with leakage outcomes than PAs located in other states. It is logical that sustainable-use PAs, where some resource extraction is allowed, showed little evidence of leakages and were associated with blockages in the best model, as looser land-use restriction is less likely to displace clearing pressure (i.e. create leakage) than strict bans on human land uses. Assuming that PA permanence is upheld, strict conservation units in the southern and western regions of Amazônia Legal should continue to be monitored for leakage over time, especially considering the worsening magnitude of annual leakage for the PAs that showed net leakage by 2017 (Fig. 5).

Although we identified few paper parks and few leakages, two major threats related to leakage of deforestation pressure from PA establishment remain. First, the few cases of high magnitude leakage we detected could have displaced habitat conversion pressure to non-target areas that are more vulnerable or irreplaceable than the PA target area itself. Thus, the key principles of systematic conservation planning, irreplaceability and vulnerability (Margules and Pressey 2000), should still be rigorously applied to prioritize areas for conservation in the Amazon, and conservation planners should make a concerted effort to consider the species richness in the area targeted for protection as well as the species richness of the associated spillover zones (Renwick et al. 2015) to avoid a perverse outcome of opportunistic protection (Barnes et al. 2018). Second, the increasing magnitude of (non-cumulative) leakage over time (Fig. 5) indicates that net leakage may continue to increase in the future; as such, we recommend that as new data becomes available, spillover should be routinely monitored. Third, although we found very little evidence of displaced deforestation pressure in the adjacent surroundings of PAs, deforestation that would have occurred in the PA could have been displaced further afield. Indeed, two supply-chain agreements implemented to reduce deforestation in the Amazon (the Soy Moratorium and zero-deforestation beef agreement) have been found to have successfully reduced deforestation in the target region at the cost of increased clearing of native vegetation in the Cerrado biome to the south (Dou et al. 2018); it is possible that PAs established in the Amazon biome could also displace land-use change pressure to the Cerrado. Implementation of a telecoupling framework would be required to identify such trans- 
biome spillover; the same holds for trans-national scale spillover (Bruckner et al. 2015; Dou et al. 2018). Total leakage could consist of development displaced both locally and further afield; we only measured local leakage. It is nonetheless important to measure the local component of leakage, especially considering that deforestation displaced from the PA is likely to occur nearby because adjacent areas are likely characterized by the same accessibility and other characteristics as the protected land (Bode et al. 2015).

There is a need for clear, widely applicable methodological guidelines for counterfactual evaluation of these local non-target impacts of PA establishment (Ferraro and Pattanayak 2006; Fuller et al. 2019; Miteva et al. 2012; Pfaff and Robalino 2017). The impossibility of estimating locally derived baselines for 18 of the 91 PAs due to the crowded nature of this region's reserve network demonstrates the practical limitations of method proposed by Ewers and Rodrigues (2008). Further, the estimation of a baseline deforestation rate from random landscape samples suggested by this method does not account for other untested environmental and anthropogenic factors that could be driving intensity of deforestation pressure. Statistical tools like propensity score matching (Andam et al. 2008; Chomitz 2002; Joppa and Pfaff 2010) and panel regression techniques (Jones and Lewis 2015) could improve these counterfactual baseline estimates. Our study attempted to account for this possible variation in likelihood of clearing by using two baselines: one highly localized to minimize environmental differences, and one state-based to minimize differences in anthropogenic factors. Our strategy may not have accounted for all possible confounding effects (Ferraro and Pattanayak 2006); the true counterfactual annual deforestation that would have occurred if no PA had ever been established cannot, by definition, be known but only estimated.

Policies targeting deforestation, such as legislation like the Forest Code of 2012 (Soares-Filho et al. 2014) or supply-chain agreements like the Soy Moratorium initiated in 2006 (Dou et al. 2018), were indirectly accounted for through generation of a baseline expectation of deforestation for each PA separately for each year. By calculating target and non-target PA impact with these annual counterfactual estimates, our analysis captured year-to-year variation in deforestation pressures. It is likely that a combination of such legislative and supply-chain regulations with permanent and enforced PAs and Indigenous Lands is necessary to optimize trade-offs between conservation and development in the Amazônia Legal region, and it is important that future studies distinguish the varying roles of these regulations and associated human migrations (e.g. illegal land appropriation by grileiros). We assessed the impact of 91 PAs' only upon deforestation rates, but it is important to acknowledge that the land-use restrictions associated with PAs may also impact other anthropogenic pressures on biodiversity and carbon, such as forest degradation, hunting, introduction of invasive species, hydroelectric energy generation and transportation, mining, or road construction. It is important to also account for the social and ethical dimensions of PA establishment for local residents and indigenous peoples (Miller et al. 2011).

The extent to which the results of our impact assessments and spillover accounting for deforestation inhibition by PAs can be generalized beyond the study region is unclear: most of the PAs we assessed are relatively remote from densely populated cities or transportation infrastructure (for now). Future research on this region, and research on less remote regions, should pursue fine-scale analyses of accessibility, using proxies such as distance to nearest road or town. For example, it cannot be assumed that the same minimal threat that leakage of clearing pressure has posed recently in Amazônia Legal translates to habitats that are already highly fragmented by development, such as the Atlantic Forest, or that are characterized by other types of land cover, such as the Cerrado. These two other Brazilian biomes are both global biodiversity hotspots where habitat is highly threatened by land-use changes (Myers et al. 2000); assessing the target and nontarget impacts of the PAs and other conservation interventions in these and other biodiversity hotspots, where data is available, should be a global priority. 


\section{Conclusion}

427 Regardless of location, it is crucial to ensure that PAs are truly additional, permanent (Kroner et al. 428 2019; Mascia and Pailler 2011; Pack et al. 2016), enforced, and that their achievements are not 429 offset by leakage. PAs are the cornerstone of conservation of ecosystems, species, and genetic 430 diversity globally; impactful forested PAs are also important for climate change mitigation goals. Our 431 counterfactual impact assessments suggests that most PAs established since 2005 in Amazônia Legal have successfully inhibited deforestation within their boundaries, and, in the majority of cases, this inhibition of clearing has not displaced deforestation pressures to PAs' adjacent, unprotected surroundings. Leakage mitigation as part of the systematic conservation planning for this region is, therefore, not imperative. For the most effective conservation of Amazonian forests, priority should instead be given to achieving additionality with any new PA and ensuring the permanence and enforcement of those already established. 


\section{References}

Andam, K.S., Ferraro, P.J., Pfaff, A., Sanchez-Azofeifa, G.A., Robalino, J.A., 2008. Measuring the effectiveness of protected area networks in reducing deforestation. Proceedings of the National Academy of Sciences of the United States of America 105, 16089-16094. 10.1073/pnas.0800437105.

Aukland, L., Costa, P.M., Brown, S., 2003. A conceptual framework and its application for addressing leakage: The case of avoided deforestation. Climate Policy 3, 123-136. 10.1016/S14693062(02)00065-7.

Barnes, M.D., Glew, L., Wyborn, C., Craigie, I.D., 2018. Prevent perverse outcomes from global protected area policy. Nature ecology \& evolution 2, 759-762

Bode, M., Tulloch, A.I.T., Mills, M., Venter, O., W. Ando, A., 2015. A conservation planning approach to mitigate the impacts of leakage from protected area networks. Conservation Biology 29, 765-774. 10.1111/cobi.12434.

Bruckner, M., Fischer, G., Tramberend, S., Giljum, S., 2015. Measuring telecouplings in the global land system: A review and comparative evaluation of land footprint accounting methods. Ecological Economics 114, 11-21. 10.1016/j.ecolecon.2015.03.008.

Chomitz, K.M., 2002. Baseline, leakage and measurement issues: How do forestry and energy projects compare. Climate Policy 2, 35-49. 10.1016/S1469-3062(02)00011-6.

Di Minin, E., Toivonen, T., 2015. Global protected area expansion: creating more than paper parks. BioScience 65, 637-638. 10.1093/biosci/biv064.

Dou, Y., da Silva, R.F.B., Yang, H., Liu, J., 2018. Spillover effect offsets the conservation effort in the Amazon. Journal of Geographical Sciences 28, 1715-1732. 10.1007/s11442-018-1539-0.

Ewers, R.M., Rodrigues, A.S.L., 2008. Estimates of reserve effectiveness are confounded by leakage. Trends in Ecology and Evolution 23, 113-116. 10.1016/j.tree.2007.11.008.

Fearnside, P.M., 2008a. The roles and movements of actors in the deforestation of Brazilian Amazonia. Ecology and Society 13.

Fearnside, P.M., 2008b. The value of protected areas in avoiding climate change in Amazonia. Updating of priority areas for conservation, Sustainable use and sharing of the biodiversity Benefits-Amazon. Biome 2008, 8-11.

Fearnside, P.M., 2009. Carbon benefits from Amazonian forest reserves: Leakage accounting and the value of time. Mitigation and Adaptation Strategies for Global Change 14, 557-567. 10.1007/s11027-009-9174-9.

Ferraro, P.J., 2009. Counterfactual thinking and impact evaluation in environmental policy. New Directions for Evaluation 2009, 75-84.

Ferraro, P.J., Pattanayak, S.K., 2006. Money for nothing? A call for empirical evaluation of biodiversity conservation investments. PLoS Biology 4, e105. 10.1890/14-2274.1.

Ferreira, L.V., Venticinque, E., Almeida, S., 2005. O desmatamento na Amazônia e a importância das áreas protegidas. Estudos avançados 19, 157-166.

Freitas, F.L., Sparovek, G., Berndes, G., Persson, U.M., Englund, O., Barretto, A., Mörtberg, U., 2018. Potential increase of legal deforestation in Brazilian Amazon after Forest Act revision. Nature Sustainability 1, 665. 
Fuller, C., Ondei, S., Brook, B.W., Buettel, J.C., 2019. First, do no harm: A systematic review of deforestation spillovers from protected areas. Global Ecology and Conservation, e00591.

Griscom, B.W., Adams, J., Ellis, P.W., Houghton, R.A., Lomax, G., Miteva, D.A., Schlesinger, W.H., Shoch, D., Siikamäki, J.V., Smith, P., 2017. Natural climate solutions. Proceedings of the National Academy of Sciences 114, 11645-11650.

Herrera Garcia, L.D., 2015. Protected Areas' Deforestation Spillovers and Two Critical Underlying Mechanisms: An Empirical Exploration for the Brazilian Amazon, p. 104. Duke University, Ann Arbor.

Herrera, D., Pfaff, A., Robalino, J., 2019. Impacts of protected areas vary with the level of government: Comparing avoided deforestation across agencies in the Brazilian Amazon. Proceedings of the National Academy of Sciences 116, 14916-14925.

James, G., Witten, D., Hastie, T., Tibshirani, R., 2013. An Introduction to Statistical Learning with Applications in R. Springer Science+Business Media, New York.

Jones, K.W., Lewis, D.J., 2015. Estimating the counterfactual impact of conservation programs on land cover outcomes: the role of matching and panel regression techniques. PLOS ONE. 10.1371/journal.pone.0141380.

Joppa, L., Pfaff, A., 2010. Reassessing the forest impacts of protection. Annals of the New York Academy of Sciences 1185, 135-149. 10.1111/j.1749-6632.2009.05162.x.

Kroner, R.E.G., Qin, S., Cook, C.N., Krithivasan, R., Pack, S.M., Bonilla, O.D., Cort-Kansinally, K.A., Coutinho, B., Feng, M., Garcia, M.I.M., 2019. The uncertain future of protected lands and waters. Science $364,881-886$. (cited on lines 346 and 430)

Mascia, M. B., \& Pailler, S. (2011). Protected area downgrading, downsizing, and degazettement (PADDD) and its conservation implications. Conservation Letters , 4 (1), 9-20. https://doi.org/10.1111/j.1755-263X.2010.00147.x

Margules, C.R., Pressey, R.L., 2000. Systematic conservation planning. Nature 405, 243. $10.1038 / 35012251$.

Miller, T.R., Minteer, B.A., Malan, L.-C., 2011. The new conservation debate: the view from practical ethics. Biological Conservation 144, 948-957.

Miteva, D.A., Pattanayak, S.K., Ferraro, P.J., 2012. Evaluation of biodiversity policy instruments: what works and what doesn't? Oxford Review of Economic Policy 28, 69-92. 10.1093/oxrep/grs009.

Mittermeier, R.A., Mittermeier, C.G., Brooks, T.M., Pilgrim, J.D., Konstant, W.R., Da Fonseca, G.A., Kormos, C., 2003. Wilderness and biodiversity conservation. Proceedings of the National Academy of Sciences 100, 10309-10313.

Myers, N., Mittermeier, R.A., Mittermeier, C.G., Da Fonseca, G.A., Kent, J., 2000. Biodiversity hotspots for conservation priorities. Nature 403, 853.

Nagendra, H., 2008. Do parks work? Impact of protected areas on land cover clearing. AMBIO: A Journal of the Human Environment 37, 330-337. 10.1579/06-R-184.1.

Naughton-Treves, L., Holland, M.B., Brandon, K., 2005. The role of protected areas in conserving biodiversity and sustaining local livelihoods. Annu. Rev. Environ. Resour. 30, 219-252.

Nelson, A., Chomitz, K.M., 2011. Effectiveness of strict vs. multiple use protected areas in reducing tropical forest fires: a global analysis using matching methods. PLoS ONE 6, e22722. 
Nepstad, D., Schwartzman, S., Bamberger, B., Santilli, M., Ray, D., Schlesinger, P., Lefebvre, P., Alencar, A., Prinz, E., Fiske, G., 2006. Inhibition of Amazon deforestation and fire by parks and indigenous lands. Conservation Biology 20, 65-73. 10.1111/j.1523-1739.2006.00351.x

Nepstad, D.C., Stickler, C.M., Filho, B.S.-., Merry, F., 2008. Interactions among Amazon land use, forests and climate: prospects for a near-term forest tipping point. Philosophical Transactions of the Royal Society B: Biological Sciences 363, 1737-1746.

Nolte, C., Agrawal, A., Silvius, K.M., Soares-Filho, B.S., 2013. Governance regime and location influence avoided deforestation success of protected areas in the Brazilian Amazon. Proceedings of the National Academy of Sciences 110, 4956-4961.

Oliveira, P.J.C., Asner, G.P., Knapp, D.E., Almeyda, A., Galván-Gildemeister, R., Keene, S., Raybin, R.F., Smith, R.C., 2007. Land-use allocation protects the Peruvian Amazon. Science 317, 12331236. $10.1126 /$ science. 1146324.

Ostwald, M., Henders, S., 2014. Making two parallel land-use sector debates meet: Carbon leakage and indirect land-use change. Land Use Policy 36, 533-542.

10.1016/j.landusepol.2013.09.012.

Pack, S. M., Ferreira, M. N., Krithivasan, R., Murrow, J., Bernard, E., \& Mascia, M. B. (2016). Protected area downgrading, downsizing, and degazettement (PADDD) in the Amazon. Biological Conservation , 197 , 32-39. https://doi.org/10.1016/j.biocon.2016.02.004

Pfaff, A., Robalino, J., 2017. Spillovers from Conservation Programs. Annual Review of Resource Economics 9, 299-315. 10.1146/annurev-resource-100516-053543.

Pfaff, A., Robalino, J., Herrera, D., Sandoval, C., 2015a. Protected areas' impacts on Brazilian Amazon deforestation: examining conservation-development interactions to inform planning. PLoS ONE 10.

Pfaff, A., Robalino, J., Lima, E., Sandoval, C., Herrera, L.D., 2014. Governance, location and avoided deforestation from protected areas: greater restrictions can have lower impact, due to differences in location. World Development 55, 7-20.

Pfaff, A., Robalino, J., Sandoval, C., Herrera, D., 2015b. Protected area types, strategies and impacts in Brazil's Amazon: public protected area strategies do not yield a consistent ranking of protected area types by impact. Philosophical Transactions of the Royal Society B: Biological Sciences 370, 20140273.

Pimm, S.L., Raven, P., 2000. Biodiversity: extinction by numbers. Nature 403, 843.

Pressey, R., Humphries, C., Margules, C.R., Vane-Wright, R., Williams, P., 1993. Beyond opportunism: key principles for systematic reserve selection. Trends in ecology \& evolution 8, 124-128.

Pressey, R.L., Weeks, R., Gurney, G.G., 2017. From displacement activities to evidence-informed decisions in conservation. Biological Conservation 212, 337-348. 10.1016/j.biocon.2017.06.009.

Renwick, A.R., Bode, M., Venter, O., 2015. Reserves in Context: Planning for Leakage from Protected Areas. PLoS ONE 10. 10.1371/journal.pone.0129441.

Richards, P., Arima, E., VanWey, L., Cohn, A., Bhattarai, N., 2017. Are Brazil's deforesters avoiding detection? Conservation Letters 10, 470-476.

Robalino, J., Pfaff, A., Villalobos, L., 2017. Heterogeneous Local Spillovers from Protected Areas in Costa Rica. Journal of the Association of Environmental and Resource Economists 4, 795820. 10.1086/692089. 
Schuster, R., Germain, R.R., Bennett, J.R., Reo, N.J., Arcese, P., 2019. Vertebrate biodiversity on indigenous-managed lands in Australia, Brazil, and Canada equals that in protected areas. Environmental Science \& Policy 101, 1-6.

Soares-Filho, B., Moutinho, P., Nepstad, D., Anderson, A., Rodrigues, H., Garcia, R., Dietzsch, L., Merry, F., Bowman, M., Hissa, L., Silvestrini, R., Maretti, C., 2010. Role of Brazilian Amazon protected areas in climate change mitigation. Proceedings of the National Academy of Sciences of the United States of America 107, 10821-10826. 10.1073/pnas.0913048107.

Soares-Filho, B., Rajão, R., Macedo, M., Carneiro, A., Costa, W., Coe, M., Rodrigues, H., Alencar, A., 2014. Cracking Brazil's forest code. Science 344, 363-364.

Tapia-Armijos, M.F., Homeier, J., Munt, D.D., 2017. Spatio-temporal analysis of the human footprint in South Ecuador: Influence of human pressure on ecosystems and effectiveness of protected areas. Applied Geography 78, 22-32. 10.1016/j.apgeog.2016.10.007.

UNEP-WCMC and IUCN (2019), Protected Planet: The World Database on Protected Areas (WDPA)/The Global Database on Protected Areas Management Effectiveness (GD-PAME), September 2019 version, Cambridge, UK: UNEP-WCMC and IUCN. Available at: www.protectedplanet.net.

Vitel, C., Fearnside, P.M., Graça, P., 2009. Análise da inibição do desmatamento pelas áreas protegidas na parte Sudoeste do Arco de desmatamento. Anais XIV Simpósio Brasileiro de Sensoriamento Remoto, Natal, Brasil, 6377-6384. 


\section{Display Items}

N.B.: Color should be used for any figures in print.

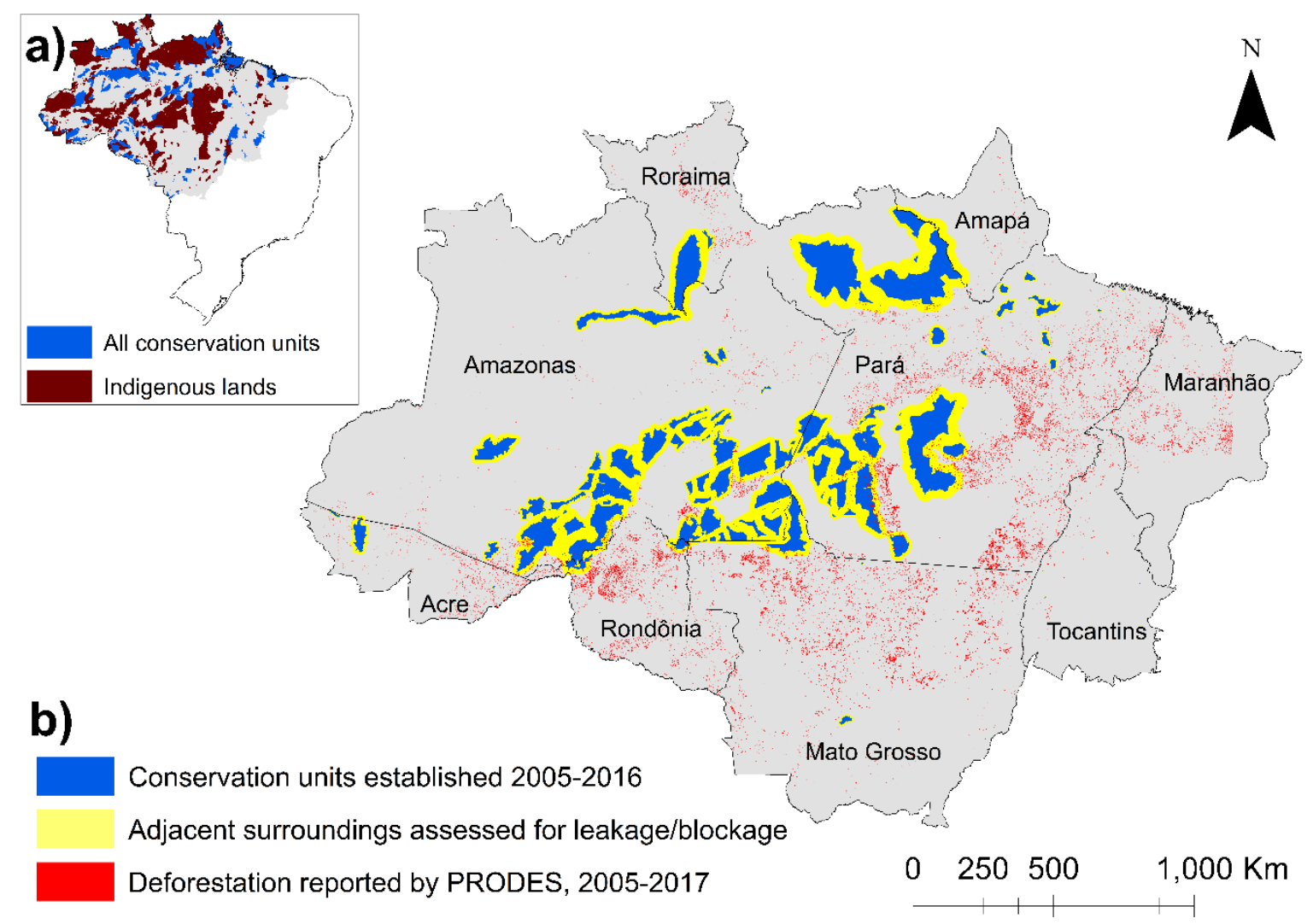

Figure 1. The inset map (a) shows the position of the Amazônia Legal (grey) within Brazil and the location of all the conservation PAs and indigenous lands ever established in the region. Indigenous lands were not assessed for impacts on deforestation, but were accounted for (see online supporting information, Table S1) where they overlapped with the spillovers zones of the PAs assessed. The main map (b) of the study region, Amazônia Legal, shows the 91 PAs that were established within it from 2005 to 2016 (blue), their adjacent zones tested for possible spillover (yellow), and areas of new deforestation reported for each year 2005 to 2017 (red). Government of the region is administered through nine Brazilian states, which are labelled in the main map (b). 


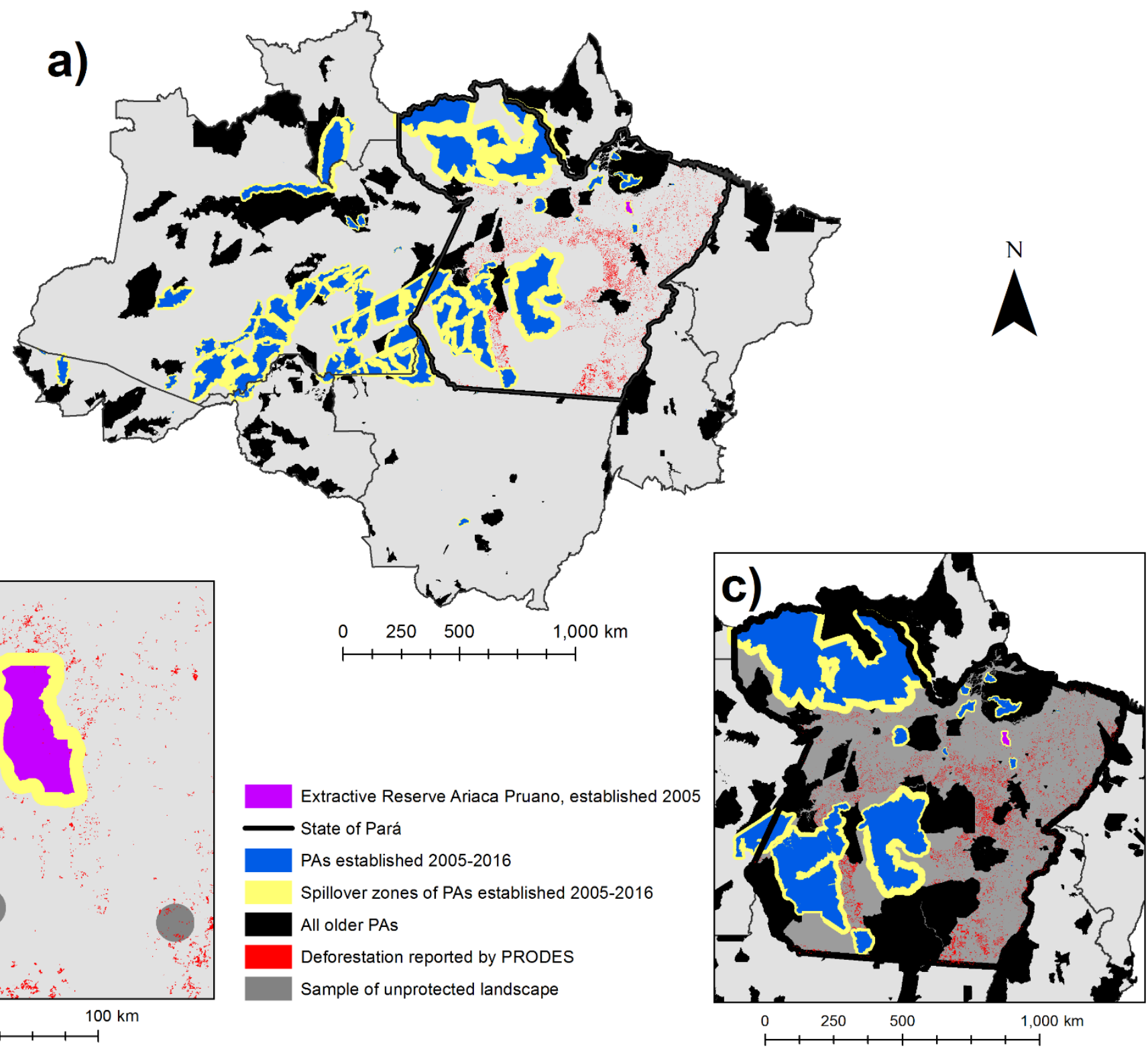


Figure 2. Maps of unprotected areas sampled to estimate two baseline deforestation rates for the Extractive Reserve Ariaca Pruano. A baseline is an estimate of the area of new deforestation that might have been expected in the PA and in its adjacent unprotected surroundings (yellow) had no protection ever been declared in the area. Deforestation (red) was reported during the period 2005 to 2016. The main map (a) shows the location of the Extractive Reserve Ariaca Pruano (purple) and the state of Pará (heavy outline) within Amazônia Legal. The left-hand inset map (b) was adapted from the non-target impact assessment method proposed by Ewers and Rodrigues (2008): five randomly generated circular samples (dark grey) of the nearby, unprotected landscape (light grey) were used to estimate expected deforestation for each year in the PA and in the spillover zone. The combined area of the five samples is equal to the area of the PA and thus also equal to the area of the spillover zone. The right-hand inset map (c) shows a novel spatial sample from which an alternative baseline is derived from the entire unprotected portion of the state within which the PA is located, which in this case is Pará. 


\section{Spatial data acquisition}
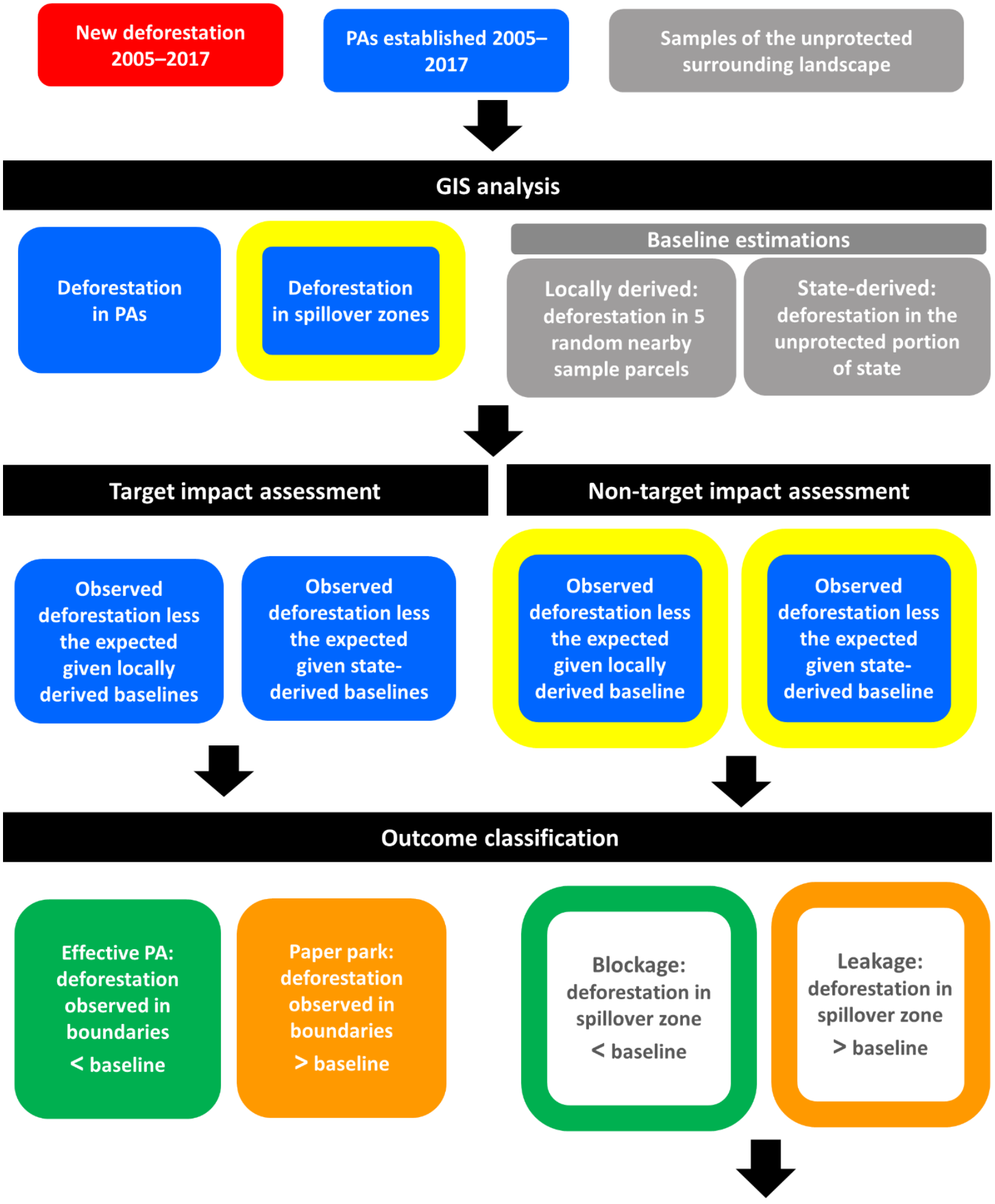

\section{Statistical analysis}

Model results from locally derived baselines
Model results from statederived baselines 
601 Figure 3. Sequence of methods used to acquire relevant data, to assess the target (blue) and nontarget (yellow) impacts of PA establishment, to classify PAs as leakage generating (orange) or blockage generating (green), and finally to analyze the results of the non-target impact assessments. The impact assessment, outcome classification, and statistical analysis steps were performed for two data sets, one generated using locally derived baselines (73 spillover results) and the other generated using the state-derived baselines (91 spillover results). 
Impacts calculated with locally derived baselines
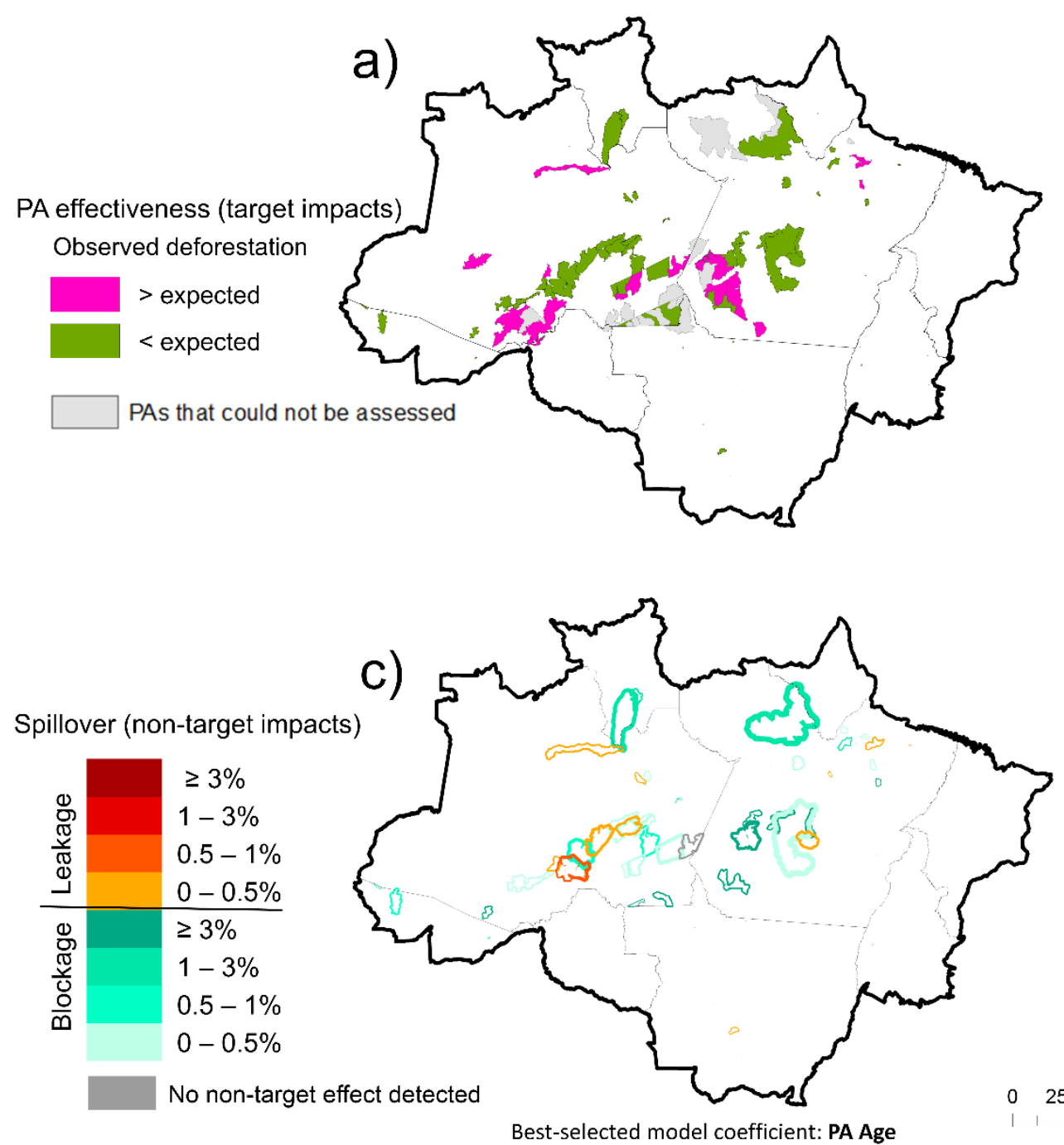

Impacts calculated with state-derived baselines

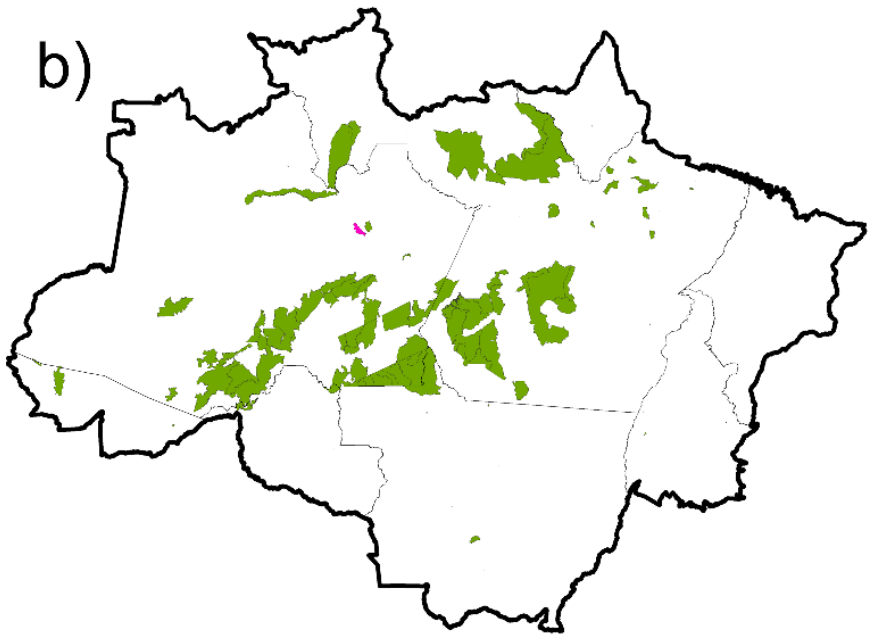

$\hat{\Lambda}$

250500

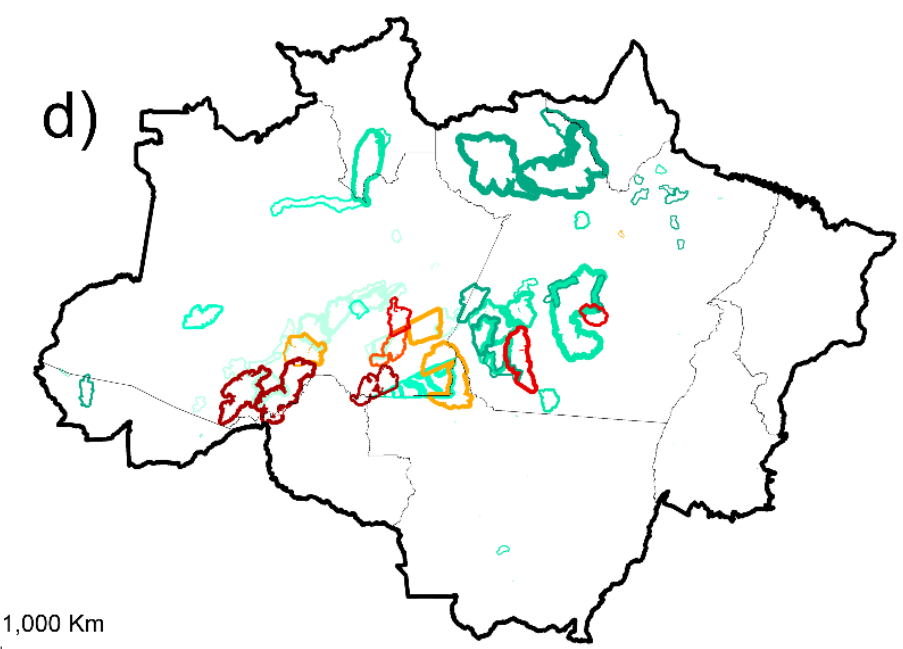

Best-selected model coefficients: PA Age, State, Sustainable Use versus Conservation Unit 
Figure 4. Maps of color-coded target and non-target (i.e. spillover) impacts identified after the establishment of 91 PAs in the Amazônia Legal since 2005, showing the impact of protection within the PAs as calculated (a) with locally derived baselines, and (b) with state-derived baselines. The impact of protection in the local spillover zones was also calculated (c) with locally derived baselines, and (d) with state-derived baselines. Spillover results are not shown for those PAs that experienced more deforestation within their boundaries than expected, as these PAs were unlikely to have influenced their surroundings if protection did not influence their target areas. 
a) Locally derived

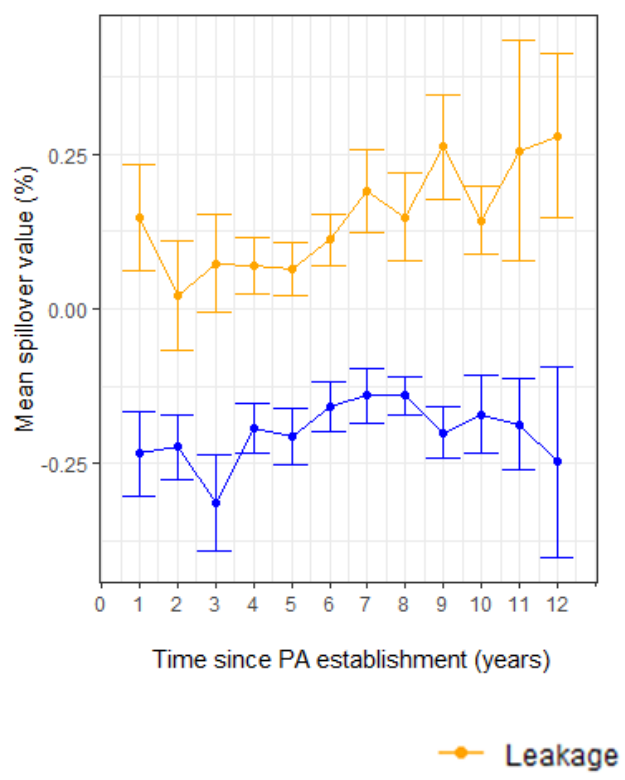

b) State-derived

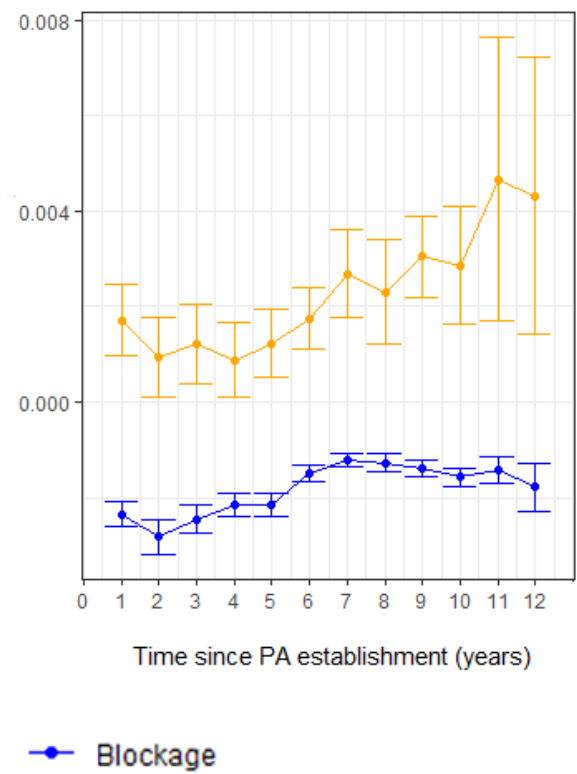

617 Figure 5. Plot of mean annual spillover value per PA age class, using both (a) locally derived baselines 618 and (b) state-derived baselines, with the net outcome of either leakage ( $n=9$ and $n=11$, respectively) in orange or blockage ( $n=34$ and 79 , respectively) plotted separately. The error bars show the standard error of each mean. Note the difference in the y-axes' scales between plot (a) and (b). 